\title{
Initial Experience of Retroperitoneoscopic Surgery in Benign Renal Diseases
}

\author{
Ashok Kumar Kunwar, ${ }^{1}$ Amit Mani Upadhyay, ${ }^{1}$ Sanjesh Bhakta Shrestha, ${ }^{1}$ Udaya Koirala, ${ }^{1}$ Kabir Tiwari, ${ }^{1}$ \\ Ganesh Dangal² \\ ${ }^{1}$ Department of Surgery, ${ }^{2}$ Department of Obstetrics and Gynecology, Kathmandu Model Hospital, Exhibition \\ Road, Kathmandu, Nepal.
}

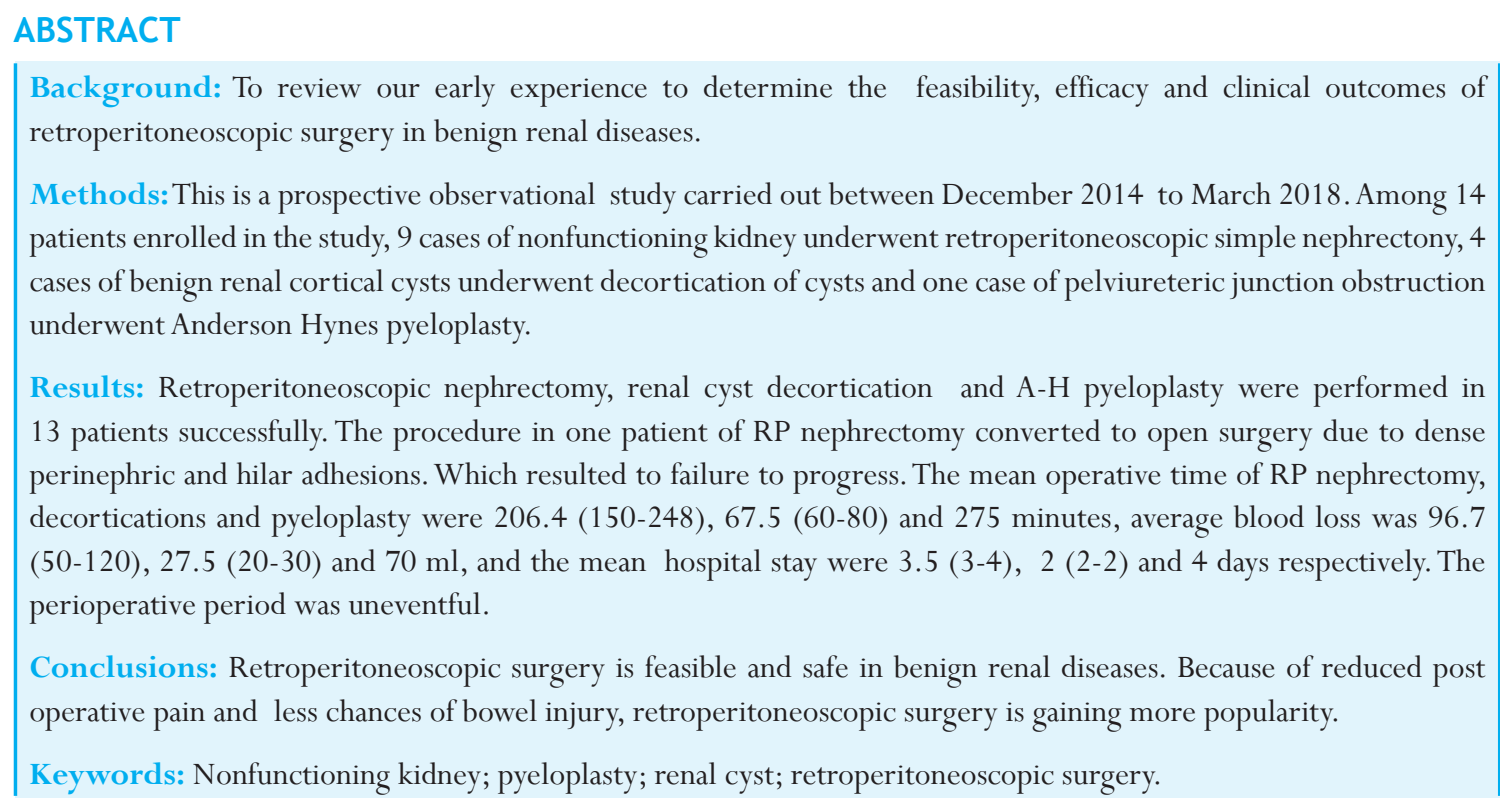

\section{INTRODUCTION}

Management of benign renal diseases has undergone a drastic change in last few decades. Retroperitoneoscopic surgery has gained popularity due to numerous advantages. The clinical breakthrough was a transperitoneal laparoscopic nephrectomy performed by Clayman et $\mathrm{al}^{1}$ in 1991 . Retroperitoneoscopic approach came into limelight after the initial description by Gaur by using a balloon dissection technique. The first retroperitoneoscopic nephrectomy was performed by Gaur ${ }^{2}$ in 1993. Laparoscopic renal cyst decortication was first described by Hulbert and colleagues ${ }^{3}$ as a good alternative and definitive advantages to open surgery in 1992. Adjacent organ injury is very less, unlike in the transperitoneal approach, and there is very minimal risk of peritonitis. Janetschek et $\mathrm{al}^{4}$ were the first author to describe retroperitoneoscopic pyeloplasty for PUJ obstruction in 1996.

The retroperitoneoscopic techniques are increasingly used for benign renal diseases. Here we report our early experience to determine the feasibility, efficacy and clinical outcomes of retroperitoneoscopic surgery in benign renal diseases.

\section{METHODS}

This is a prospective observational study of 14 patients who underwent retroperioneoscopic surgery at Kathmandu Model Hospital. The study period was between Dec 2014 to March 2018, nine cases of nonfunctioning kidney underwent retroperitoneoscopic simple nephrectomy, four cases undergone decortication of renal cysts and one case of PUJ obstruction underwent A-H pyeloplasty (Table 1 ).

Retroperitoneoscopy was performed with 3 ports technique in a standard lateral kidney position. A skin incision $(2 \mathrm{~cm})$ was made in the mid axillary line midway between the iliac crest and the $12 \mathrm{rib}$. The incision was extended through the muscles and dorsolumbar fascia. A digital dissection was made in the retroperitoneal space pushing the peritoneum anteriorly and displacing

\footnotetext{
Correspondence: Ashok Kumar Kunwar, Department of Surgery, Kathmandu Model Hospital,Exhibition Road, Kathmandu, Nepal, Email: kunwar_ashok@ hotmail.com Phone:+977 9841258139.
} 
the fat from the abdominal wall to accommodate the balloon. The retroperitoneal space was created by using a Gaur's ${ }^{2}$ balloon made of sterile glove. The Gour's balloon was placed in the space and filled with 300 $500 \mathrm{ml}$ normal saline. The Hasson's trocar was placed and fixed at the body wall to avoid air leakage. $\mathrm{A} \mathrm{CO}_{2}$ insufflation was performed at a pressure of $12 \mathrm{mmHg}$ to create pneumoretroperitoneum. A zero degree laparoscopic lense was introduced by the Hasson port and two secondary ports $(10 \mathrm{~mm}$ and $5 \mathrm{~mm}$ ) were placed at the anterior and posterior axillary line around $5 \mathrm{~cm}$ above the iliac crest. Three ports were used routinely. (Figure. 1,2)

The psoas muscle is the main anatomic landmark. This muscle was dissected and the ureter and the gonadal vein in the left or the inferior vena cava in the right were identified. The renal vein was dissected in the right side following the vena cava and the renal artery was dissected over the renal vein. In the left side, the renal vein was identified following the gonadal vein and the artery was found just above the renal vein. The approach to vascular pedicle was done posteriorly and vessels were clipped by metal and Hem-o-lok (Weck Closure Systems, North Carolina, USA) clips. After vascular control by clipping the renal artery and vein, kidney was mobilized from pericapsular plane inside the gerota's fascia. In all of the cases adrenal gland was preserved. The lower pole then dissected and the ureter was clipped with a titanium clip. In gross hydronephrotic kidneys the fluid in the collecting system was aspirated to facilitate perirenal dissection. The specimen was entrapped in a handmade bag. In cases where the samples are small, we utilized the primary port to retrieve the specimen and with larger samples we prolonged the incision. Finally, a $16 \mathrm{~F}$ tube drain was left in retroperitoneal space and the ports were closed.

\section{Table 1. Patients demography and retroperitoneoscopy procedures.}

\begin{tabular}{|c|c|c|c|c|c|}
\hline Age/Sex & $\begin{array}{l}\text { Operated } \\
\text { Side }\end{array}$ & Symtoms & Preoperative Investigations & Diagnosis & $\begin{array}{l}\text { Operative } \\
\text { Procedure }\end{array}$ \\
\hline $27 / F$ & Right & Flank pain & $\begin{array}{l}\text { USG, CTU, DTPA renogram } \\
\text { GFR } 0\end{array}$ & $\begin{array}{l}\text { Nephrolithiasis with } \\
\text { NFK }\end{array}$ & Nephrectomy \\
\hline $28 / F$ & Right & $\begin{array}{l}\text { Flank pain, } \\
\text { fever }\end{array}$ & $\begin{array}{l}\text { USG, CTU, DTPA renogram } \\
\text { GFR } 5\end{array}$ & $\begin{array}{l}\text { Nephrolithiasis with } \\
\text { NFK }\end{array}$ & $\begin{array}{l}\text { Converted to open } \\
\text { nephrectomy }\end{array}$ \\
\hline $32 / F$ & Left & Flank pain & $\begin{array}{l}\text { USG, CTU, DTPA renogram } \\
\text { GFR } 3\end{array}$ & $\begin{array}{l}\text { Nephrolithiasis with } \\
\text { NFK }\end{array}$ & Nephrectomy \\
\hline $49 / F$ & Right & Flank pain & $\begin{array}{l}\text { USG, CTU, DTPA renogram } \\
\text { GFR } 0\end{array}$ & PUJO with NFK & Nephrectomy \\
\hline $44 / M$ & Right & $\begin{array}{l}\text { Flank pain, } \\
\text { fever }\end{array}$ & $\begin{array}{l}\text { USG, CTU, DTPA renogram } \\
\text { GFR } 4\end{array}$ & $\begin{array}{l}\text { Nephrolithiasis with } \\
\text { NFK }\end{array}$ & Nephrectomy \\
\hline $36 / M$ & Left & Flank pain & $\begin{array}{l}\text { USG, CTU, DTPA renogram } \\
\text { GFR } 0\end{array}$ & PUJ calculus with NFK & Nephrectomy \\
\hline $30 / M$ & Right & Flank pain & $\begin{array}{l}\text { USG, CTU, DTPA renogram } \\
\text { GFR } 0\end{array}$ & PUJ calculus with NFK & Nephrectomy \\
\hline $40 / F$ & Right & Flank pain & $\begin{array}{l}\text { USG, CTU, DTPA renogram } \\
\text { GFR } 0\end{array}$ & PUJO with NFK & Nephrectomy \\
\hline $53 / M$ & Left & $\begin{array}{l}\text { Flank pain, } \\
\text { fever }\end{array}$ & $\begin{array}{l}\text { USG, CTU, DTPA renogram } \\
\text { GFR } 4\end{array}$ & PUJ calculus with NFK & Nephrectomy \\
\hline $42 / M$ & Right & Flank pain & $\begin{array}{l}\text { CTU, } 6 \times 5 \mathrm{~cm} \text { lower pole } \\
\text { renal cyst, Bosniak I }\end{array}$ & Renal cyst & $\begin{array}{l}\text { Decortication of } \\
\text { renal cyst }\end{array}$ \\
\hline $24 / M$ & Right & Flank pain & $\begin{array}{l}\text { CTU, } 7 \times 7 \mathrm{~cm} \text { upper pole } \\
\text { renal cyst, Bosniak I }\end{array}$ & Renal cyst & $\begin{array}{l}\text { Decortication of } \\
\text { renal cyst }\end{array}$ \\
\hline $44 / M$ & Left & Flank pain & $\begin{array}{l}\text { CTU, } 5 \times 5 \mathrm{~cm} \text { lower pole } \\
\text { renal cyst, Bosniak I }\end{array}$ & Renal cyst & $\begin{array}{l}\text { Decortication of } \\
\text { renal cyst }\end{array}$ \\
\hline $32 / M$ & Right & Flank pain & $\begin{array}{l}\text { CTU, } 7 \times 6 \mathrm{~cm} \text { mid pole } \\
\text { renal cyst, Bosniak I }\end{array}$ & Renal cyst & $\begin{array}{l}\text { Decortication of } \\
\text { renal cyst }\end{array}$ \\
\hline $7 / M$ & Left & Flank pain & $\begin{array}{l}\text { USG, CTU, DTPA } \\
\text { Renogram, DF, L 40\%, R 60\% }\end{array}$ & PUJ obstruction & A-H pyeloplasty \\
\hline
\end{tabular}

DTPA, diethylenetriamine pentaacetic acid; NFK, nonfunctioning kidney; GFR, glomerular filtration rate; DF, differential function; USG, ultrasonogram; CTU, computed tomography urogram. 
In case of retroperitoneoscopic A-H pyeloplasty, threeport approach was used with stay suture placed to hold the renal pelvis. The retroperitoneal space was created with similar methods as in RP nephrectomy. The ureter was identified and traced to the pelviureteric junction. A dismembered pyeloplasty was carried out using 5-0 vicryl running sutures after placing the double $\mathrm{J}$ stent in antegrade fashion. Little reduction of the renal pelvis was carried out due to roomy extrarenal pelvis. A perinephric drain was placed and ports were closed (Figure 3).

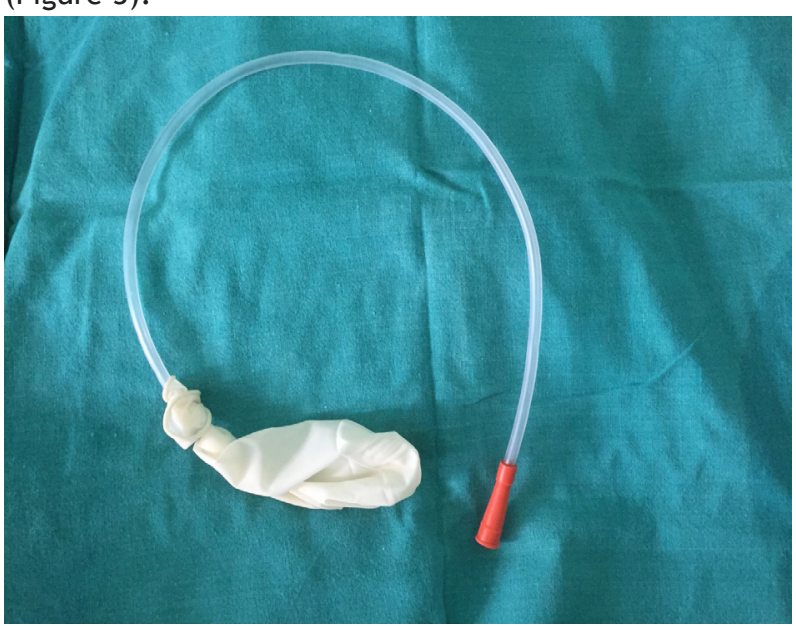

Figure 1. Gaur's balloon made of a suction tube 14F and a sterile glove.

In case of renal cyst decortications, kidneys were mobilized through the pericapsular region after opening

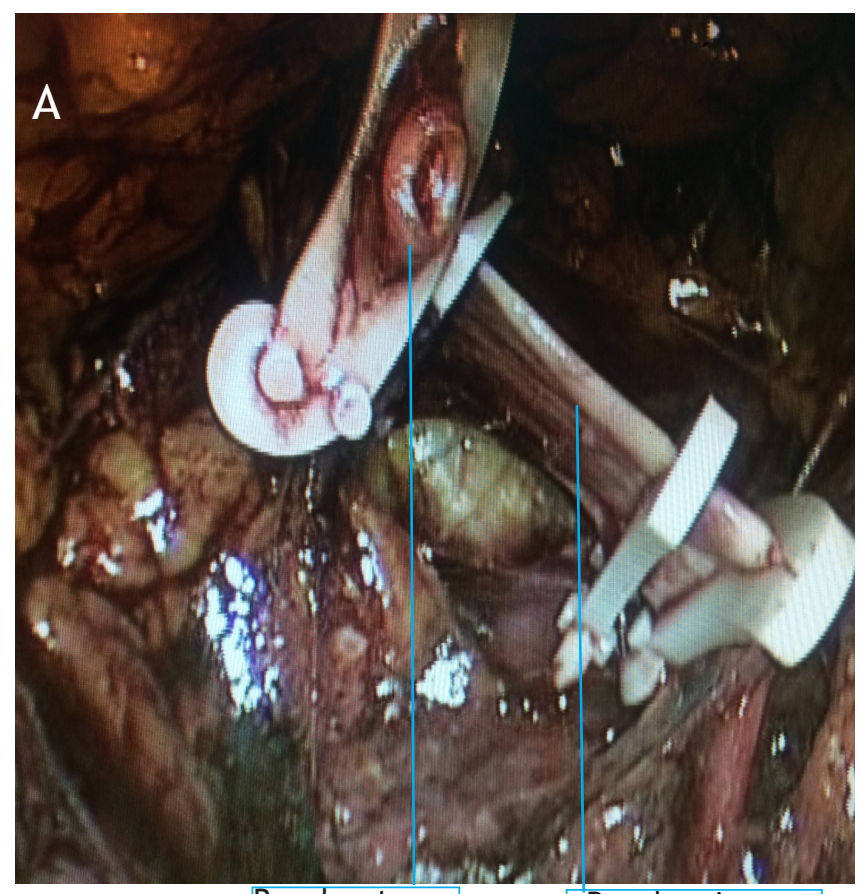

Renal artery Renal vein the gerota's fascia. The cyst appeared in most cases as a blue dome, which was then dissected and its edge was delivered. The cyst contents were aspirated, and the aspirate was sent for cytological analysis. The roof of the cyst was then excised using endoscissors and monopolar hooks. The edge of the renal cyst after deroofing, hemostasis achieved by electrocautery, and the perirenal fat was placed over the base of the cyst. Finally, a tube drain was placed and the wounds were closed (Figure 4).

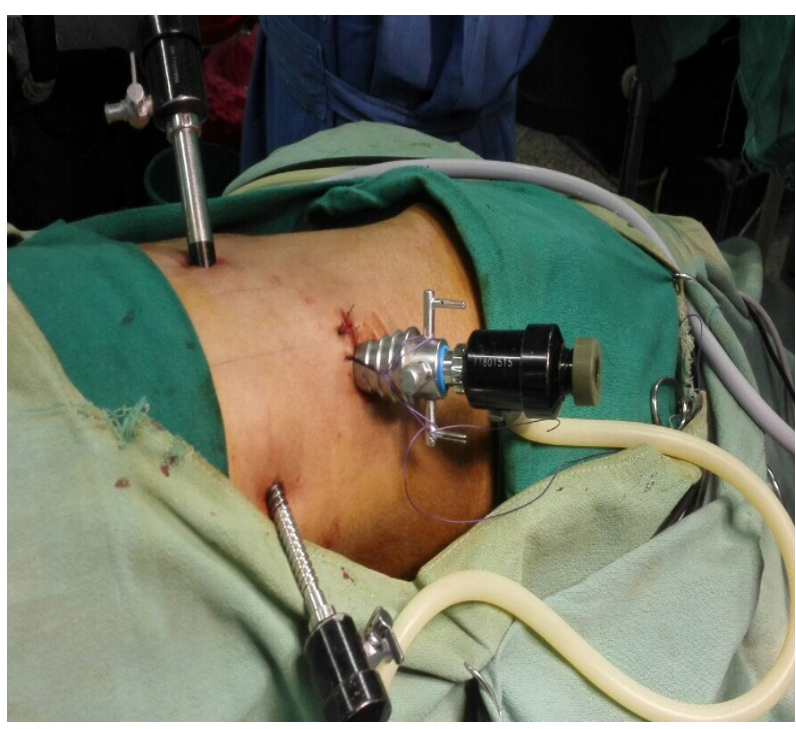

Figure 2. Surface view of right RP nephrectomy. Hasson's open technique for trocar placement.

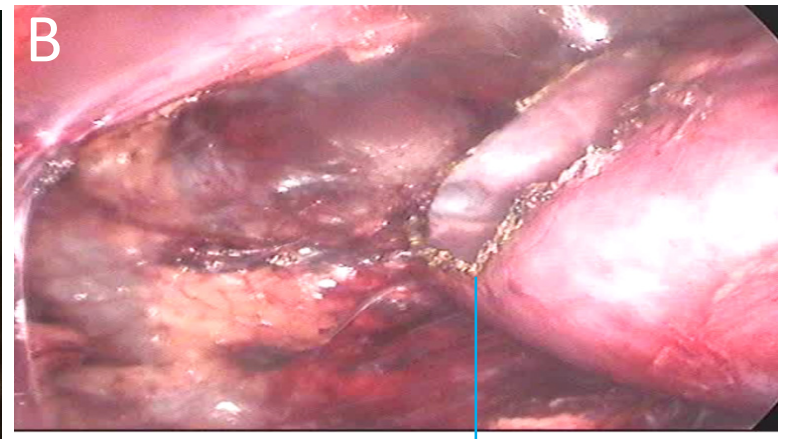

Kidney after decortication of cyst

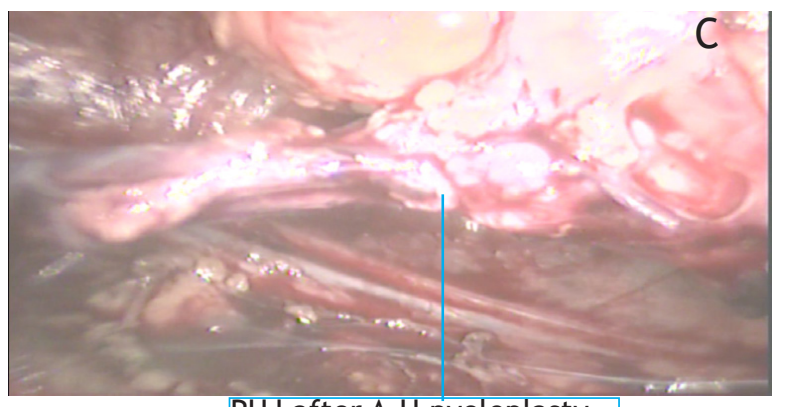

PUJ after A-H pyeloplasty

Figure 3. Intraoperative pictures. (A) Hem-o-lok clips to control renal vessels during RP nephrectomy. (B) RP decortication of renal cyst. (C) RP A-H pyeloplasty for PUJ obstruction. 


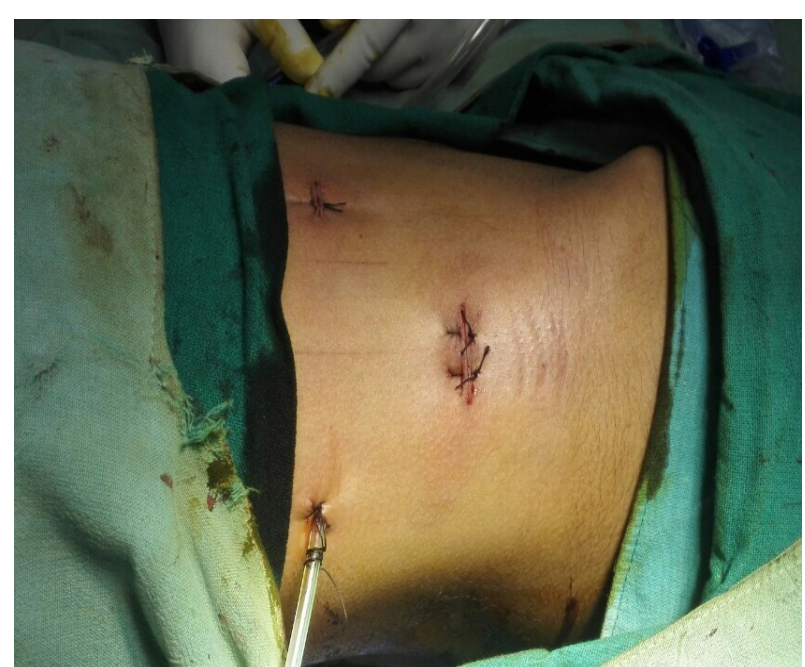

Figure 4. Final view of the incisions.

\section{RESULTS}

All of the surgeries were performed by a single surgeon. Retroperitoneoscopic nephrectomy, renal cyst decortication and A-H pyeloplasty were performed in 14 patients successfully. Overall, the mean operative time of nephrectomy, decortications and pyeloplasty were 206.4 (150-248), $67.5(60-80)$ and 275 minutes, estimated blood loss were 96.7 (50-120), 27.5 (20-30) and $70 \mathrm{ml}$, and the mean length of hospital stay were $3.5(3-4), 2$ (2-2) and 4 days respectively. (Table. 2)

The procedure in one patient of RP nephrectomy needed conversion to open surgery due to chronic pyelonephritis resulting dense perinephric and hilar adhesions. which in turn contributed to failure to progression of the procedure.
One patient developed intraoperative bleeding around $10 \mathrm{ml}$ from the renal vein during pedicle dissection but controlled with a titanium clip. No major perioperative complication occurred. Postoperative period was uneventful in all the patients with three patients had postoperative complication Clavien Dindo grade I. One patient with pyonephrosis developed superficial surgical site infection and two patients developed minor surgical emphysema around the primary port site which disappeared 12 hours after the surgery without any interventions.

In majority of the cases of nephrectomy and decortications of renal cyst, specimens were retrieved from the primary port site without extending the incision due to loss of renal parenchyma with resultant small size kidney. But, In two patients needed extension of primary port site up to $3-4 \mathrm{~cm}$ due to large renal stones and specimens to retrieve the kidneys.

Aspiration of the cyst showed a clear fluid with negative cytology in all renal cysts. No malignancy was detected on histopathological examination of the cyst walls and kidneys. Follow up of the patients with nephrectomy was done in every 6 months by serum creatinine and ultrasonography of kidney, ureter and bladder (KUB). All the patients were symptoms free with normal serum creatinine and ultrasonography KUB in nephrectomy group. All patients following decortication were followed up for 6-12 months, assessing pain and cyst recurrence. No recurrence of renal cyst in follow up and all the patients were asymtomatic. Successful resolution of PUJ obstruction was observed in pyeloplasty patient, had significant improvement in hydronephrosis and symptoms free up to 12 months follow up.

Table 2. Detailed data of the Retroperitoneoscopy procedures.

\begin{tabular}{|c|c|c|c|c|c|c|c|}
\hline Procedures & $\begin{array}{l}\text { No of } \\
\text { cases }\end{array}$ & $\begin{array}{r}\text { Mean } \\
\text { Age, yrs } \\
\text { (range) }\end{array}$ & $\begin{array}{r}\text { Male/ } \\
\text { Female }\end{array}$ & $\begin{array}{r}\text { Mean } \\
\text { Operative } \\
\text { Time, mins } \\
\text { (range) }\end{array}$ & $\begin{array}{r}\text { Mean Blood Loss, } \\
\text { ml (range) }\end{array}$ & Compli-cations & $\begin{array}{r}\text { Hospital Stay, } \\
\text { days (range) }\end{array}$ \\
\hline Nephrectomy & 9 & $\begin{array}{r}36 \\
(27-49)\end{array}$ & $5 / 4$ & $\begin{array}{r}206.4 \\
(150-248)\end{array}$ & $\begin{array}{r}96.7 \\
(50-120)\end{array}$ & $\begin{array}{r}3 \text { (clavien } \\
\text { dindo grade I) }\end{array}$ & $3.5(3-4)$ \\
\hline $\begin{array}{l}\text { Renal Cyst } \\
\text { Decortication }\end{array}$ & 4 & $\begin{array}{r}35.5 \\
(24-44)\end{array}$ & $3 / 1$ & $\begin{array}{r}67.5 \\
(60-80)\end{array}$ & $\begin{array}{r}27.5 \\
(20-30)\end{array}$ & 0 & $2(2)$ \\
\hline $\begin{array}{l}\text { A-H } \\
\text { Pyeloplasty }\end{array}$ & 1 & 7 & $1 / 0$ & 275 & 70 & 0 & 4 \\
\hline
\end{tabular}




\section{DISCUSSION}

Simple nephrectomy, dismembered pyeloplasty and decortication of renal cyst are the most common procedures for the benign renal diseases. Open surgery has more postoperative morbidities so minimally invasive technique has been established due to less morbidity. Management of benign renal diseases has undergone drastic change in last few decades. Retroperitoneoscopy for treating benign renal disease of the upper urinary tract has become widely preferred and established approach in many outstanding urology centers around the world after description of the Gaur's technique. ${ }^{5}$

The advantages of retroperitoneoscopic over transperitoneal approach are the lack of bowel mobilization with a resultant decrease in intraoperative bowel injury and postoperative ileus, rapid and direct kidney and renal hilum access, the avoidance of peritoneal cavity contamination and a lower incidence of long-term complications, ie port site hernia and bowel obstruction. ${ }^{6,7}$ The main disadvantage of the retroperitoneoscopy is reduced working space compared with transperitoneal approach requiring a synchronized surgical team to avoid instrument collision, which has been solved after use of Gaur's balloon creating a large working space.

Absolute contraindication of the retroperitoneoscopy is the previous open retroperitoneal surgery. Relative contraindications are the chronic inflammatory pathologies such as renal tuberculosis and xanthogranulomatous pyelonephritis. The frequency of conversion was around $9 \%$ in simple laparoscopic nephrectomy and most commonly due to the hemorrhage and perinephric adhesions. ${ }^{4,8}$ In our study, one of the case for RP nephrectomy converted to open surgery due to chronic pyelonephritis and pyonephrosis resulted to failure to progress. This case was the second case of our series and converted to open nephrectomy.

In our present study, the mean oprerative time for retroperitoneoscopic nephrectomy was 206.4 minutes (range, 150-248 $\mathrm{min}$ ). In one of the study by Garg et al 9, prospective randomized comparison of transperitoneal vs retroperitoneal laparoscopic simple nephrectomy. Mean operating time was significantly less in retroperitoneoscopic nephrectomy group. Sebe et al 8 , found the mean operating time of 114 minutes (range, 35-280 $\mathrm{min}$ ) in their study of retroperitoneoscopic nephrectomy. Not only in the benign renal diseases, in the comparative study of transpetitoneal vs retroperitoneal radical nephrectomy conducted by Desai et al ${ }^{10}$ also concluded that the retroperitoneal approach had shorter time for renal vascular control and shorter total operative time (207 vs 150 minutes; $P=0$.001). In recent systematic review in retroperitoneoscopy in urology, Lombardo $\mathrm{R}$ and collegue ${ }^{11}$ concluded that retroperitoneoscopic approach in urological diseases is a valid alternative to the transperitoneal approach and evidence suggest lower morbidity for the retroperitoneoscopic approach however technical complexity may limit its widespread. In our series, the last two cases were performed using harmonic scalpel replacing bipolar Maryland dissector for kidney dissection, which resulted in significant decrease in the operating time and found significant decrease in operative time. In the future we believe that our operative time will be more comparable to the other standard study by improving surgical technique with complete laparoscopic armamenterium.

In our study, we successfully performed one retroperitoneoscopic A-H dismembered pyeloplasty without any perioperative complication and the operative time was 275 mins. The operative time was longer in our study compared with the prospective randomized comparision between transperitoneal laparoscopic pyeloplasty and retroperitoneoscopic pyeloplasty conducted by Singh $\mathrm{V}$ et $\mathrm{al}^{12}$ in 112 patients, the mean operative time was 188.21 mins. for primary PUJ obstruction in retroperitoneoscopic group. We believe that the operating time will decrease gradually in the days to come with more number of cases.

RP dismembered pyeloplasty was associated with low rate of ileus, less postoperative pain and shorter hospital stay in comparison to the transperitoneal laparoscopic pyeloplasty. Although the success rate remains the same for both procedures. Valla $\mathrm{JS}^{13}$ found the retroperitoneoscopic method has superior cosmetic result than the transperitoneal approach.

In our series, we performed total 4 cases of retroperitoneoscopic decortications of renal cyst. The mean operative time was $67.5(60-80)$ mins, estimated blood loss was $27.5(20-30) \mathrm{ml}$ and total hospital stay was 2 days, which were comparable with other studies. Ozcan et al ${ }^{14}$, conducted a retrospective study comparing retroperitoneal vs laparoscopic decortications of renal cyst in 40 patients and concluded that the retroperitoneal approach to be the first choice because of its shorter operation time and particularly low level of postoperative pain.

Anaesthesia related complications has been found to be less in retroperitoneoscopic approach than in 
transperitoneal approach during nephrectomy from a study by El-tohamy et al ${ }^{15}$. The authors concluded that during retroperitoneoscopy ventilatory, hemodynamic, and cerebral functions are less deleterious compared to transperitoneal laparoscopy which shows retroperitoneal surgeries are safe even in long procedures than in transperitoneal approach.

In present study, there was no major complication recorded and the majority of complications were Clavien Dindo grade I according to Dindo-modified Clavien classification of surgical complications which was managed conservatively. Overall complication rate was $25.8 \%$ in transperitoneal and $12.9 \%$ in retroperitoneal nephrectomy group in the study conducted by Garg et al, ${ }^{9}$ which was comparable with our study. Patients were asymptomatic in the follow-up period without late postoperative complications.

\section{CONLCLUSIONS}

Retroperitoneoscopic approach was safe and effective method for simple nephrectomy, decortication of renal cyst and $\mathrm{A}-\mathrm{H}$ dismembered pyeloplasty. Because of the reduced post operative pain and less chances of bowel injury, we recommend retroperitoneoscopic surgery is a safe approach in benign renal diseases.

\section{REFERENCES}

1. Clayman RV, Kavoussi LR, Soper NJ, Dierks SM, Merety KS, Darcy MD, et al. Laparoscopic nephrectomy. N Engl J Med. 1991;324:1370-1. [PubMed]

2. Gaur DD, Agrawal DK, Purohit KC. Retroperitoneal laparoscopic nephrectomy: initial case report. J Urol. 1993;149:103-5.[PubMed]

3. Hulbert JC. Laparoscopic management of renal cystic disease. Semin Urol. 1992;10:239- 41.[PubMed]

4. Janetschek G, Peschel R, Altarac S, Bartsch G. Laparoscopic and retroperitoneoscopic repair of ureteropelvic junction obstruction. Adult Urology. 1996; 47: 311-6.[PubMed]

5. Gupta NP, Goel R, Hemal AK, Dogra PN, Seth A, Aron $\mathrm{M}$, et al. Should retroperitoneoscopic nephrectomy be the standard of care for benign nonfunctioning kidneys? An outcome analysis based on experience with 449 cases in a 5-year period. J Urol. 2004;172:1411-3.[PubMed]

6. Hemal AK, Gupta NP, Kumar R. Comparison of retroperitoneoscopic nephrectomy with open surgery for tuberculous nonfunctioning kidneys. J Urol. 2000;164:325. Science Direct]

7. Zhang X, Zheng T, Ma X, Li HZ, Li LC, Wang SG, et al.
Comparison of retroperitoneoscopic nephrectomy versus open approaches to nonfunctioning tuberculous kidneys: a report of 44 cases. J Urol. 2005;173:1586-9.[PubMed]

8. Sebe P, de la Taille A, Hoznek A, Chopin D, Abbou CC, Salomon L. Simple nephrectomy with retroperitoneal laparoscopy. Prog Urol. 2003;13:577-80.[PubMed]

9. Garg M, SinghV, Sinha RJ, Sharma P. Prospective randomized comparison of transperitoneal vs retroperitoneal laparoscopic simple nephrectomy. Urology. 2014; 84:33539.[PubMed]

10. Desai MM, Strzempkowski B, Matin SF, Steinberg AP, Ng C, Meraney AM, et al. Prospective randomized comparison of transperitoneal versus retroperitoneal laparoscopic radical nephrectomy. J Urol. 2005;173:38-41. [PubMed]

11. Lombardo R, Martos R, Ribal MJ, Alcaraz A, Tubaro A, De Nunzio C, et al. Retroperitoneoscopy in urology: a systematic review. Minerva Urol Nefrol. 2019 Jan 2.[PubMed]

12. Singh V, Sinha RJ, Gupta DK, Kumar V, Pandey M, Akhtar A, et al. Prospective randomized comparison between transperitoneal laparoscopic pyeloplasty and retroperitoneoscopic pyeloplasty for primary ureteropelvic junction obstruction. JSLS. 2014;18(3).[PubMed]

13. Valla JS. Retroperitoneoscopic surgery in children. Semin Pediatr Surg. 2007;16:270-7. [PubMed]

14. Ozcan L, Polat EC, Onen E, Cebeci OO, Memik O,Voyvoda $\mathrm{B}$, et al. Comparison between Retroperitoneal and Transperitoneal Approaches in the LaparoscopicTreatment of BosniakType I Renal Cysts: A Retrospective Study. Urol J. 2015 Sep 4;12(4):2218-22. [PubMed]

15. El- tohamy SA, Shello HM. Retroperitoneal versus transperitoneal laparoscopy for simple nephrectomy. Egypt J Anaesth. 2013;29:109-16. [Link] 